\title{
Academic research networks: Accessing resources for English-medium publishing
}

\author{
Mary Jane Curry ${ }^{\mathrm{a}, *}$, Theresa M. Lillis ${ }^{\mathrm{b}}$ \\ ${ }^{a}$ Warner Graduate School of Education and Human Development, PO Box 270425, Dewey Hall, \\ University of Rochester, Rochester, NY 14627, USA \\ ${ }^{\mathrm{b}}$ Centre for Language and Communication, Faculty of Education and Language Studies, Briggs Building, \\ The Open University, Walton Hall, Milton Keynes MK7 6AA, UK
}

\begin{abstract}
Multilingual scholars located outside of Anglophone contexts face growing pressure to publish in English. Evidence from a longitudinal "text-ethnographic" study exploring how 50 psychology and education scholars in southern and central Europe are responding to such pressure indicates that individual linguistic and rhetorical competence alone are usually insufficient for securing publication in English-medium journals. Rather, scholars' accounts demonstrate that participation in academic research networks functions as a key resource for publishing. This article examines the importance of networks and tracks how scholars gain access to and participate in them. We present 'network histories' that map out the network participation of four scholars, foregrounding several core dimensions: local and transnational, formal and informal, strong and weak, durable and temporary. Our findings suggest that strong, local, durable networks are crucial to enabling scholars' participation in transnational networks, which support their publishing in both English and local languages. Findings contribute directly to our understandings about academic publishing in a global context and to broader debates about the efficacy of initiatives for increasing research collaboration such as those sponsored by the EU Framework Programmes. We conclude by briefly considering implications for supporting multilingual scholars' publication and programmes aimed at increasing collaboration.
\end{abstract}

(c) 2010 Elsevier Ltd. All rights reserved.

Keywords: English, Networks; Scholarly publishing; Multilingual scholars; Research productivity

\section{Introduction}

As English has become the dominant language of global scholarly publishing, concomitant pressure has been mounting for multilingual scholars to publish in English, particularly in English-medium journals (Belcher, 2007; Curry \& Lillis, 2004; Flowerdew, 2000). In many contexts outside of Anglophone 'centre' locations (Wallerstein, 1991), English-medium publishing has come to be highly valued by institutional reward systems,

\footnotetext{
* Corresponding author. Tel.: +1 5852735934 (office); fax: +1 5854737598.

E-mail addresses: mjcurry@warner.rochester.edu (M.J. Curry), t.m.lillis@open.ac.uk (T.M. Lillis).
} 
factored into evaluation practices at key career moments from hiring to promotion and tenure to obtaining funding (Lillis \& Curry, 2006a, 2010; Polo \& Varela, 2009). In addition, English-medium publications offer a forum for multilingual scholars to disseminate their research broadly. Equally important, publications from outside the Anglophone centre benefit global knowledge production by broadening the range of contributions in terms of new knowledge and different perspectives. Over the past two decades, researchers have documented not only the linguistic and rhetorical resources involved in publishing in English (e.g., Flowerdew, 2001; Swales, 2004; Uzuner, 2008), but also the 'non-discursive' resources necessary for securing publication (Canagarajah, 1996, 2002). These resources can be material (e.g., supplies, equipment, Internet access, research and clerical assistance), financial (teaching release time, funds for travel or help with manuscripts), and social (e.g., colleagues, supervisors, collaborators, journal and book editors). The availability of these resources to scholars varies considerably across geopolitical contexts, most notably between centre and periphery (Wallerstein, 1991), but also within the 'centre', including stark variations within one key geopolitical centre zone, the European Union (Lillis \& Curry, 2010).

A key finding from our nine-year longitudinal study exploring the experiences of psychology and education scholars from four national contexts is that network participation enables the mobilization of resources that are essential for English-medium publication, particularly in 'high status' English-medium journals ${ }^{1}$ : these include making connections with others; obtaining information and research/bibliographic materials; collaborating on research and writing; receiving rhetorical/linguistic support; getting help with responding to feedback from gatekeepers; and securing publishing opportunities (Lillis \& Curry, 2006a, 2010). These resources are accessed via participation in academic research networks, which constitute a form of 'social capital' (Bourdieu, 1985; Portes, 2000) that is invaluable within the competitive economy of knowledge production, by supporting scholars' publishing in English. While recognizing that other factors play a role in securing Englishmedium publishing, as noted above, in this article we focus on how scholars gain access to and participate in different types of networks, and what publications - in particular, English-medium — result from such participation. In so doing, a key aim is to challenge the emphasis within much ESP/EAP research and pedagogy that foregrounds individual competence (Lillis \& Curry, 2006a, 2010) and to identify salient characteristics of network participation that support or lead to English-medium publication. ${ }^{2}$ In seeking out these characteristics, however, we are mindful of broader debates occurring in the past decade about whether formal initiatives to create scholarly networks, such as EU Framework Programmes, ${ }^{3}$ in fact result in increased productivity (Defazio, Lockett, \& Wright, 2009; Melin, 2000; Wagner \& Leydesdorff, 2005). We begin by summarizing the larger study from which the data for this article are drawn and situating this paper in the literature on academic literacies and social networks. We then present four case studies, which we call 'network histories', drawing on social capital theories and social network analysis to illustrate a range of experiences by multilingual scholars as they participate in different types of networks over time as well as the consequences of their participation. We conclude by briefly considering measures to help scholars increase their access to the networks supporting English-medium publishing and the relevance of this discussion to debates about institution-led attempts to foster research networks.

\section{The larger study}

Since 2001 we have been investigating the English-medium academic writing and publishing experiences of 50 multilingual European scholars in the fields of education and psychology (Curry \& Lillis, 2004; Lillis \& Curry, 2006a, 2006b, 2010). Our study sites-Hungary, Slovakia, Spain and Portugal-form part of the 'Expanding Circle' of English language users (Kachru, 2001), where English increasingly functions as a key instrumental language. Our larger theoretical framework draws on social practice theories of academic literacy/ies, which view social activities as underpinning all types of communication (Barton \& Hamilton, 1998;

\footnotetext{
${ }^{1}$ By 'high status journals' we mean those included, and ranked highly in, the prestigious indexes compiled by the ISI (Institute for Scientific Information), which often have an 'impact factor' (see Lillis \& Curry, 2010, for details).

2 Elsewhere we have documented multilingual scholars' commitments to publishing in their local languages for their local communities as well as in additional languages (Curry \& Lillis, 2004; Lillis \& Curry, 2010).

${ }^{3}$ For EU Framework Programme 7, see http://cordis.europa.eu/fp7/home_en.html. Accessed June 3, 2010.
} 
Gee, 1998; Lea \& Street, 1998; Lillis, 2001; Street, 2003); emerging from particular cultural traditions and knowledge-construction approaches (Bazerman, 1988; Prior, 1998); and always entailing power relations (Canagarajah, 2002; Jones, Turner, \& Street, 1999). In the larger study, and used here to examine social networks, we have developed a "text-oriented ethnographic" approach that entails collecting and analysing a variety of ethnographic and textual data to understand the production of texts for publication in their contexts. ${ }^{4}$ Data collection has comprised observations of participants' activities in their contexts; between one and eight semi-structured interviews conducted (mainly in English) with each participant; ongoing communication with participants by email, post, and telephone; and the collection of drafts of scholars' texts and correspondence with publishing gatekeepers. Overall we have made 60 field visits, conducted approximately 260 interviews, and collected around 1200 texts by participants and 500 items of correspondence between participants and others, in addition to collecting network diagrams and institutional and other documentary data (see Lillis \& Curry, 2010, for details). The study's longitudinal nature enables us to trace the development of texts along trajectories toward publication - by constructing some 240 Text Histories - and to obtain scholars' perspectives on their experiences. Two salient findings form the backdrop to our current focus: first, as noted, networks both constitute and afford scholars access to the resources needed for English-medium publishing (Lillis \& Curry, 2006a); and, second, that "literacy brokers" play a key role in the production of texts for publication - these include colleagues, language experts, and gatekeepers such as journal editors and reviewers (Lillis \& Curry, 2006b). Building on the idea of literacy brokers, here we propose the notion of "network brokers", that is, network members who play a pivotal role in bringing others into networks or helping them forge networks. We distinguish between literacy brokers and network brokers in that the former are directly involved in the production of texts (one or many, over time), whereas network brokers may or may not intervene directly in text production but are important in providing access to resources and opportunities for publishing. We illustrate our use of network brokers in the four network histories below and later in Section 5. Before considering network histories, we give an overview of key concepts and tools from social capital and network theories useful for analyzing and theorizing the nature and significance of networks for academic publishing.

\section{Social capital and social network theories}

Bourdieu's $(1985,1990)$ theory of forms of capital (economic, cultural, social, and symbolic) provides the overarching framework for our analysis of networks in academic text production. In contrast to cultural capital - which Bourdieu sees as the symbolic goods created and circulated within the family-the notion of social capital helps us to understand the importance of securing access to resources beyond the family:

social capital is the aggregate of the actual or potential resources which are linked to possession of a durable network of more or less institutionalized relationships of mutual acquaintance and recognition - or in other words, to membership in a group. (Bourdieu, 1985, pp. 248-249; emphasis added)

Networks provide access to social capital by creating routes along which resources flow; at the same time, networks function as social capital in their own right (Lin, 2001). Depending on their location, network members, or nodes, activate these routes - also called ties (connections, relationships) - within and between networks for particular purposes, according to what they can contribute and what resources they seek (Polodny \& Page, 1998). Fundamentally, networks operate on the basis of exchange and reciprocity, although frequently with unequal power relations among members (Plickert, Coté, \& Wellman, 2007). Social network analysis (SNA) has been used to identify and analyze a range of personal, familial, neighborhood, and workrelated networks by using survey, bibliographic, and interview methods (e.g., Scott, 1991; Wagner \& Leydesdorff, 2005; Wellman \& Berkowitz, 1988). Notions from SNA useful for charting networks include the range, or breadth and diversity of network nodes; the centrality (or lack thereof) of nodes in a network; the density/sparsity of networks, or the degree of connectedness among nodes; and the strength of ties, with both strong and weak ties contributing to the flow of resources and providing opportunities to use resources

\footnotetext{
${ }^{4}$ For more details of the ethnographic approach adopted in this study and the value of ethnography to researching writing more generally, see Lillis (2008).
} 
(Boissevain, 1987; Granovetter, 1983). Networks ties (and by implication, whole networks) can be characterized as strong or weak based on criteria such as the density of ties, the frequency and length of contact between nodes, the content and intensity of contact, and the degree of reciprocity of resources conveyed along ties (Granovetter, 1972). Most network studies have taken a synchronous view. However, some research has explored networks diachronically, with time spans ranging from six months to 10 years (Suitor, Wellman, \& Morgan, 1997). Melin (2000) found scientific networks to last about five or six years. These studies attest to the tendency of networks to "decay" over time, particularly over longer spans (Burt, 2000, 2002), with different network constituents decaying at different rates. Morgan, Neal, and Carder (1997) posit a "coreperiphery" network structure, with the core enduring and peripheral members changing more frequently.

In analysing data for network histories, we draw on several key SNA notions, including strength/weakness and durability/decay. We continue to emphasise the importance of the local and transnational nature of multilingual scholars' networks (Lillis \& Curry, 2006a, 2010, Chapter 3) and introduce, in the context of academic productivity, the characteristics of network formality and informality. We define formal networks as those intentionally fostered or supported by official bodies such as academic associations, including special interest groups (SIGs) or scientific commissions, institutions of higher education, governments, and supra-governmental bodies such as the European Union. Other formally constituted programs that support, as a by-product, the creation of networks include mobility programs such as ERASMUS. ${ }^{5}$ In contrast, we define informal networks as those arising from shared interests and goals of individual scholars, who may or may not be colleagues in a department, institution, or local context, and whose networks are typically not officially or institutionally supported. We include networks developed through post-graduate supervision as informal, given that establishing or supporting network development is not typically an explicit goal of graduate programmes.

\subsection{Network analysis in academic writing and publishing}

Whilst a growing body of research has set out to investigate writing for publication in English by multilingual scholars (see Uzuner (2008) for a useful overview of 39 empirical studies), little English for Academic Purposes (EAP) or academic literacies research has examined the role of networks in text production. In line with EAP research more generally, most studies adopt an individual competence model to explore the writer's experiences. We have argued, however, for the need to broaden this emphasis on individual cognitive, linguistic, and/or rhetorical foci to consider the wider range of activities and social connections entailed in writing (Lillis \& Curry, 2006a). Two particularly salient studies have explored academic writers' experiences as situated in networks: First, Ferenz (2005) links Israeli post-graduate students' strategic participation in various networks-academic (supervisors/professors, fellow students) and non-academic (colleagues, family, friends, neighbours) - to students' larger goals and choice of languages for producing particular texts. Second, investigating English-medium publishing by novice Japanese scholars, Casanave (1998) documents the importance of cultivating "networks of contacts" (p. 194) to learn about publishing opportunities. She traces how scholars maintained networks they had established when they were post-graduate students in the United States and found that the "well-connected scholars had better opportunities to establish themselves through their writing than did those without those connections in both the Japanese and U.S. contexts" (p. 189). ${ }^{6}$

In contrast to the aforementioned studies tracking the significance of scholarly text production, considerable use of SNA has been made in bibliometric studies; that is, studies that take published articles as data used to generate maps of hypothesised networks on the basis of co-authorship or citation of other scholars'

\footnotetext{
${ }^{5}$ Founded in 1987, the European Region Action Scheme for the Mobility of University Students is interested in transnational research cooperation (http://www.europa.eu/). It has also created an Erasmus Student Network; see http://www.esn.org/. Accessed June 3, 2010.

${ }^{6}$ Studies of writing in contexts other than academic publication adopting a network perspective include ethnographic research by Fingeret (1983) and Barton and Padmore (1994) documenting how adults call upon social networks for help in daily writing activities. Studying a middle-school student's engagement with the literacies of school and gaming, Leander and Lovvorn (2006) propose "literacy networks," which include artifacts involved in the production and circulation of literacy as members. Considering the "boundary crossing" of adult learners entering higher education, Ivanič and Satchwell (2007) suggest that literacy is "both 'situated' and 'networked"' (p. 103). Gunnarson (1997) documents the effects of the social organization of a Swedish government office on professional writing.
} 
publications (see, e.g., Carolan and Natriello (2005) on education; Moody (2004) on sociology; Newman (2001) on science). In research on the reasons for collaboration by co-authors of science articles based in one university, Melin (2000) supplemented this bibliometric approach with a questionnaire; of the 195 respondents, seven were also interviewed. The main reason scholars gave for collaboration was "gaining knowledge or skills, and gaining access to methods and equipment that the partner could provide" (p. 34). Bibliometric studies based on published data are useful in delineating network structures, but from our perspective- of aiming to explore multilingual scholars' accounts and practices - such studies are limited in that they (1) tell only about those network members who are named co-authors of published papers and not about network brokers more widely; (2) do not tell how scholars gain access to networks; and (3) do not tell about the relationship between local and transnational network activity. We now turn to analyses of our longitudinal data to explore some of these important and often backgrounded dimensions.

\section{Scholars' network access, participation, and publishing outcomes}

Here we present network histories of multilingual scholars from each of our study's four geolinguistic sites. We have selected these scholars' network histories for their epistemological status as 'telling' rather than 'typical' cases (Mitchell, 1984, p. 239), as they illuminate network participation in ways that are especially salient for understanding the practices of academic text production. We conceptualize network histories as case studies focusing on scholars' participation in networks, which are based on "detailed accounts of a particular series of events or actions of actors" (Mitchell, 1984, p. 240). These case studies can be explored at an individual level - the scholar in networks over time — or at the level of the "collective case study" (Stake, 2000, p. 437), which allows us to consider network dynamics more broadly. The four scholars represented here have participated in the research for between seven and nine years, during which we conducted between four and eight interviews with each scholar, elicited one to two network diagrams, and collected their writings for publication. The network histories draw on this data to provide a diachronic perspective that allows us to understand temporal aspects of network participation leading to scholarly publishing, which can take a considerable length of time.

The network histories consist of narratives of scholars' networks, in which we (1) document how each scholar enters or creates, contributes to, and sustains networks over time; (2) map out the role of these networks in supporting each scholar's English-medium publishing; and (3) identify resulting publications and the communities for which texts are written. We present diagrams illustrating the range and type of networks to which each scholar belongs, taking the perspective of the focal person (the 'ego' in SNA terms) rather than identifying a priori a 'whole' network (Wellman, 1999). All four scholars have high English proficiency levels. We have selected these scholars as they differ in their (sub)disciplines, gender, years working in academia, number of publications in their local languages and in English, and the nature of their participation in different types of networks. ${ }^{7}$

\subsection{Network history 1: Ornella, Hungary}

Ornella, 32, is an assistant professor in the same psychology department in Hungary where she earned her doctorate. She has participated in local and transnational, informal and formal, weak and strong networks leading to publication. To date, she has published four Hungarian-medium and six English-medium articles and book chapters.

\subsubsection{Network 1.1}

Ornella's PhD supervisor (included as LM in Fig. 1) expressly supported her writing development by coauthoring seven publications in Hungarian and English, involving her in organizing conferences, and co-presenting, with her, at seven conferences outside the country. He has also supported her longer stays in other European countries to "improve [her] English and get some new connections" (Interview, April 10, 2007).

\footnotetext{
${ }^{7}$ Names are pseudonyms. To protect authors' anonymity, given the sensitive nature of writing for publication, we also take pains to anonymise text extracts that might identify scholars, including the research topics their texts discuss (using X to represent deleted content). In addition, all four scholars have reviewed these analyses.
} 


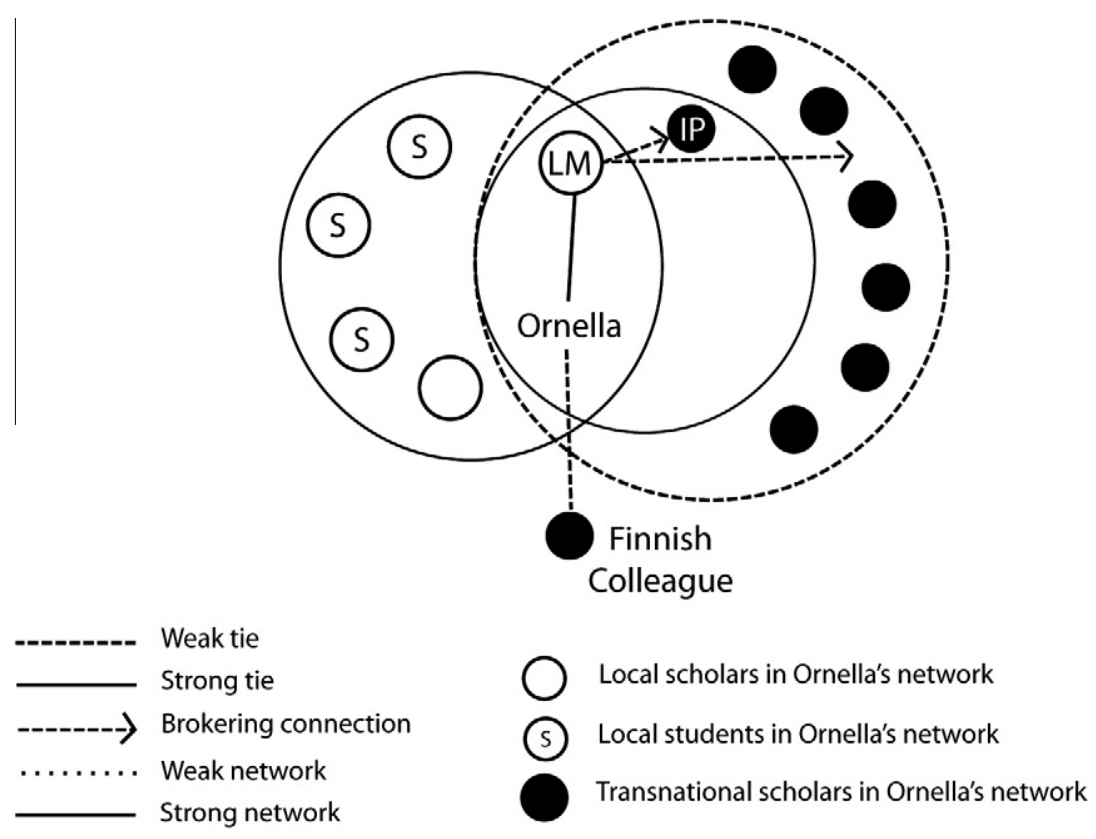

Fig. 1. Ornella's network.

While a master's student, in 2001, Ornella spent six months in Finland on an ERASMUS scholarship, during which she improved her English proficiency considerably as English was the chief medium of communication.

\subsubsection{Network 1.2}

In 2003, a Marie Curie Fellowship enabled Ornella to spend six months at a Spanish university. Earlier she had attended a conference at the same university with her PhD supervisor, who introduced her to a local scholar who gave her much literature to read. She asked this Spanish scholar (indicated as IP in Fig. 1) to be her supervisor during her fellowship; he accepted, and again gave Ornella considerable time and support:

Every week we met. I worked every day in his office and if I had any questions he answered and he asked me to 'read this text and please be critical'- so he was quite open and he accepted my knowledge, my competence, and I learned a lot from him. (Interview, June 13, 2004)

In addition to exchanging ideas and information, the Spanish scholar invited Ornella to co-author three English-medium articles. After Ornella returned to Hungary, her contact with the Spanish scholar lessened as her research focus shifted to topics that her supervisor was working on, but she hoped (and still hopes) to collaborate with him again.

\subsubsection{Network 1.3}

Taking up a faculty position at her university, Ornella has continued to collaborate with her (former) supervisor. He has included her in an application to the European Science Foundation to organize an ongoing network of scholars from six countries whom he knows through collaborations established over the years.

While maintaining this tie to her former supervisor's work, Ornella is also seeking to publish independently:

$[\mathrm{He}]$ helped us a lot, and now it's time for him to drive less our career, to step back a little bit. He has a lot of $\mathrm{PhD}$ students, his project is quite big, and they need more care. That is one reason, another reason is really to find our own words, to try to write an article by ourselves, and he lets us to make new connections and to travel. (Interview, April 10, 2007)

Ornella's network history thus spans the local, informal, strong network centred around her former $\mathrm{PhD}$ supervisor and the networks fostered by formal transnational programs. Underpinning Ornella's positive expe- 


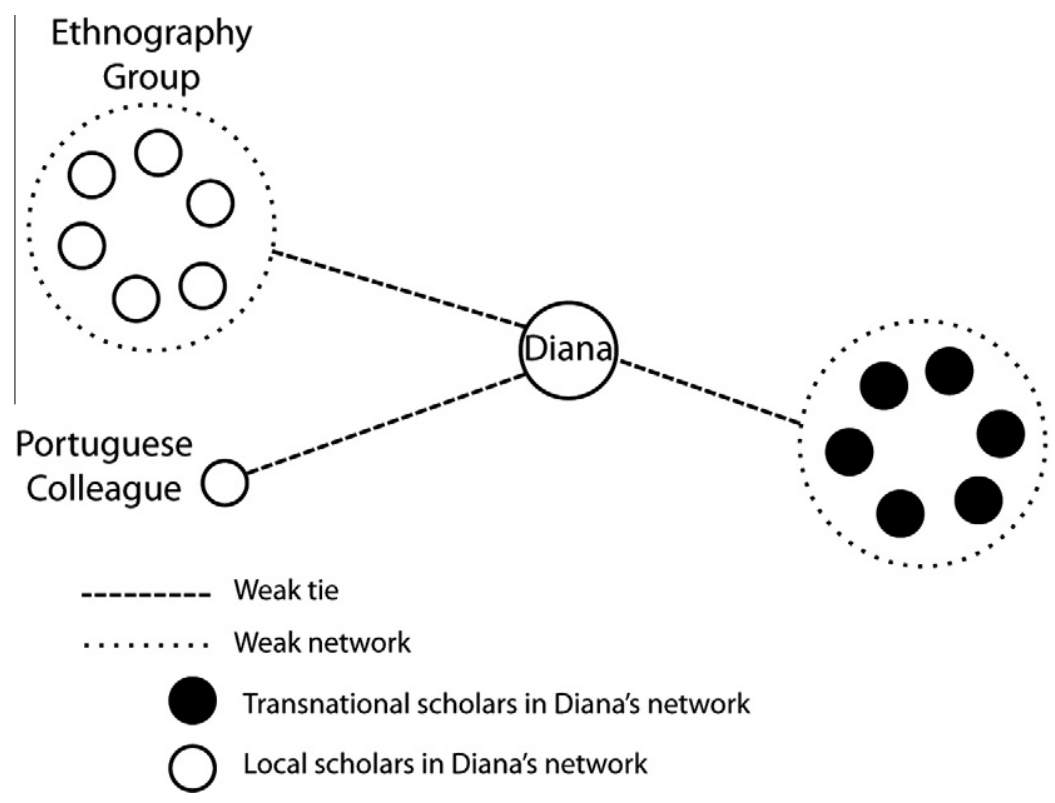

Fig. 2. Diana's network.

riences across these networks is the consistent, robust support of her $\mathrm{PhD}$ supervisor. Both he and her Spanish supervisor provided access to key resources needed for English-medium publishing: research literature, travel to conferences, and publishing opportunities. Ornella thus has strong ties in the local, informal network in which her $\mathrm{PhD}$ supervisor is the central node; his ties link her to transnational networks, such as the Spanish supervisor. The strong local ties provide a foundation for Ornella's participation in formal, transnational networks. While not every PhD student will sustain network ties as Ornella has, her network history illustrates the powerful ways that strong, local, informal networks can support participation in formal, transnational networks, which have resulted in publications in Hungarian and English. Fig. 1 presents a diagram of Ornella's academic research networks. ${ }^{8}$ It shows her strong local network comprising her supervisor (LM), another assistant professor, and her supervisor's other students, and Ornella's transnational networks, with a strong tie to the Spanish scholar (IP) and weak ties to the Finnish scholar who supervised her ERASMUS stay and to scholars in the network proposed by her PhD supervisor to the European Science Foundation.

\subsection{Network history 2: Diana, Portugal}

Diana, 51, is an "auxiliary" professor, in the Portuguese system (a rank between assistant and associate professor in the US system). She has taught for 15 years in her university's education department; however, her research interests are wide-ranging, spanning education, language, and anthropology, the field in which she earned her PhD. Having done her master's degree in an Anglophone country, and written her master's thesis in English, her English proficiency is strong. In Portuguese, Diana has published 14 articles and book chapters; in English, she has published one chapter and one article in a local Portuguese journal from her PhD research; for most of these publications she is the single author. Reflecting her range of interests, Diana participates in a number of local and transnational networks.

\subsubsection{Network 2.1}

Drawing on her anthropology background, Diana uses ethnography as her research methodology. Through a colleague who also studied with Diana's PhD supervisor, Diana is part of an "informal group of people"

\footnotetext{
${ }^{8}$ For details on the construction of these network diagrams, see Lillis and Curry (2010).
} 
interested in ethnography, but with varied research topics. With others in this network, Diana presented at a conference on ethnography and education, but no publications have resulted and publishing is not an agreed objective of the network.

\subsubsection{Network 2.2}

After presenting a poster at a conference in Vienna in 2004, Diana was invited by a Portuguese friend and colleague to contribute a chapter to a book that a Swedish scholar had enlisted the Portuguese colleague to coedit. Diana developed the chapter from the text written for her presentation and added data from her $\mathrm{PhD}$ research; the Canadian husband of a friend edited her English-medium writing. Delays ensued when the Portuguese colleague became ill and the Swedish co-editor moved to United States, but the book was eventually published in 2008. Diana was pleased to be included, as she felt the book had "a good set of articles and the people are very international, it's a very international book" (Interview, November 27, 2007). However, despite Diana's connection to this broker, because this research area diverges from her main interests, she doubts that more collaboration will ensue.

\subsubsection{Network 2.3}

One of Diana's major research interests is in a small, cutting-edge field whose proponents are located around the globe. She has become known by attending conferences and publishing in conference proceedings (to date, five English-medium papers). A Brazilian colleague also asked to reprint a Portuguese proceedings paper as a book chapter. Some members of this network have helped Diana with Englishmedium writing. For example, at a 1998 UK conference she made a connection with a New Zealand scholar who helped her with an English-medium proceedings paper. Since then Diana has met the New Zealander periodically, including at recent conferences in Mexico and Brazil where she was an invited speaker. This transcontinental network has an electronic listserv on which a call for contributions to a book was distributed. Diana's proposal was accepted, but she felt unequal to writing the chapter in English, lacking time and help in preparing a long text, and insufficient access to literature. Not completing the chapter was disappointing: "My feeling is that I lost an opportunity" (Interview, April 29, 2006). While Diana's work is clearly known and respected, she has not yet published articles in English-medium journals; nor has she developed close collaborations with colleagues who might support her. She partially ascribes this situation to what she views as a European reluctance to put one's self forward: In comparison with her knowledge of Americans, Diana feels "people in England or in Europe are much more reserved" (Interview, November 27, 2007).

The nature of Diana's range of networks is considerably different from that of Ornella. Diana's network histories indicate that, although she is a more established scholar, she has weaker ties to multiple networks, both local and transnational, and all these networks are informal. Although she has benefitted from some network brokering (e.g., the book chapter her Portuguese colleague invited her to undertake), Diana does not have the ongoing support of a strong, persistent network broker, as Ornella does. These stronger ties appear to be important for mobilizing opportunities made possible through weaker ties. Diana participates in a number of local networks; however, none seems to be strong enough to support publishing in English-medium journals. Fig. 2 illustrates the networks to which Diana has ties, which we characterize as weak, and which, although they have been fairly durable, have not fostered access to resources for English-medium publishing. Thus unlike in Ornella's network diagram (and Figs. 3 and 4), no brokering ties are indicated.

\subsection{Network history 3: Olivia, Slovakia}

Olivia, 53, is an associate professor of psychology. She has worked in academia for 28 years, mostly at her current institution, although like many Slovak scholars she also works routinely at other universities. Olivia mainly does applied research in educational psychology, stemming from her commitment to improving education in Slovakia. In Slovak she has published two books, nine book chapters, and 19 articles; in English, her publications include three book chapters and seven articles, although none in high-status journals. Her English proficiency is quite high. 

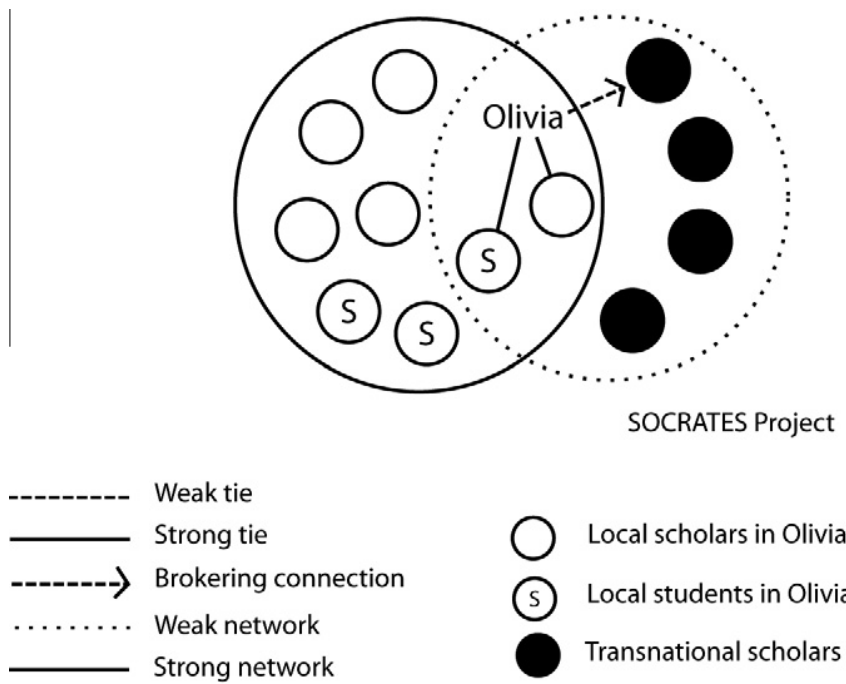

Local scholars in Olivia's network

(S) Local students in Olivia's network

Transnational scholars in Olivia's network

Fig. 3. Olivia's network.

\subsubsection{Network 3.1}

Olivia has worked for 12 years with colleagues at two of the universities with which she is connected, in some cases with research funding from the government; all three have been leaders of the Slovak branch of an international organization on their research area. Over the past decade, with one or both colleagues Olivia has co-authored at least five publications in Slovak and one in English, including co-editing a conference proceedings volume in English. With these colleagues she also supervises post-graduate students.

\subsubsection{Network 3.2}

From 2002 to 2007, Olivia participated in a multi-country project about an educational assessment (involving the United Kingdom, Spain, Denmark, and Ireland) funded by a EU SOCRATES ${ }^{9}$ program. The head of the project invited Olivia to participate as she "realised that they would need somebody from the East Europe because it may help them" obtain the grant:

The English leading person who was, her information I don't know. She addressed me, she said they were applying for some project and she needed a person who was dealing with working with teachers so I said yes I'm looking in the field of $[X]$ and I am working with teachers. (Interview, November 27, 2002)

The link to Olivia was fuzzy: another person had given Olivia's name to the researcher, who emailed Olivia the invitation to collaborate: "It was some person or connection with somebody from Slovakia who had a long path to me... I don't know!" The project undertook to adapt an English-medium assessment for use in partner countries. From the start Olivia brought her local network into the project, first in translating the manual for teachers and translating/adapting the assessment and later in using it and recording and analyzing the data:

The people who are working with me here are helpful in some ways but mainly [one of the colleagues above] is the number one who is dealing with the language as we need to translate. (Interview, November 27, 2002)

During the project, Olivia traveled to partner countries for meetings about research design, management, data collection, and analysis. With a local colleague, she published the test manual in Slovak; they are now developing publications about the project for Slovak journals. However, apart from a report to the European

\footnotetext{
9 The SOCRATES Programme (1995-2006; now the Lifelong Learning Programme) was an umbrella initiative aiming to improve education and language learning at all levels. See www.europa.eu. Accessed April 20, 2010.
} 

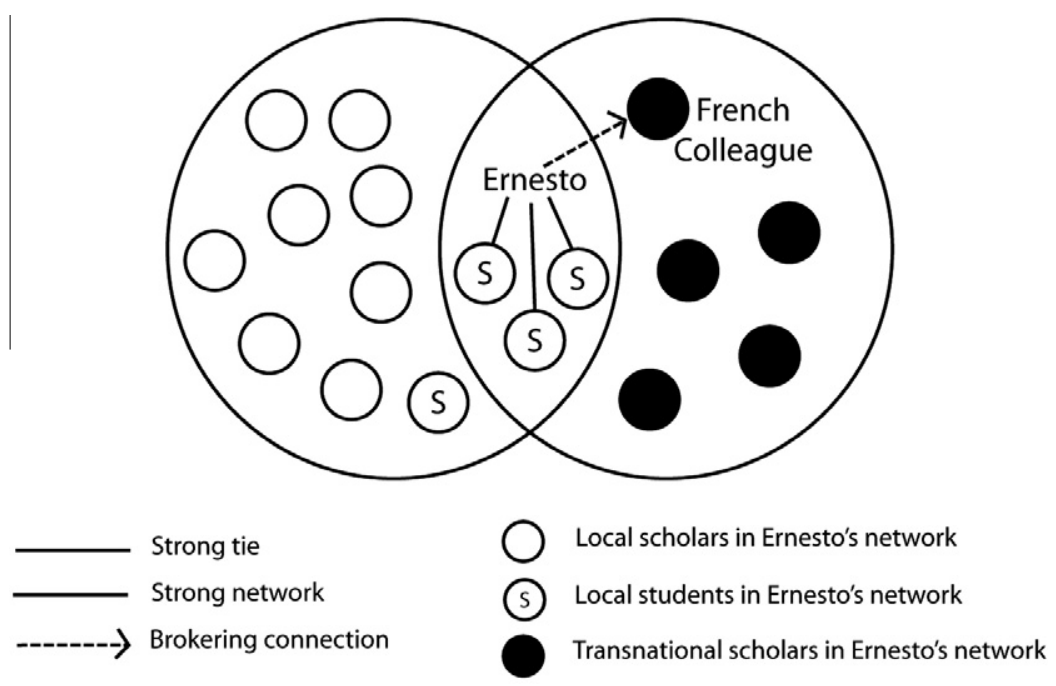

Fig. 4. Ernesto's network.

Union, no English-medium publications have resulted. While Olivia expected the UK researcher would take the lead on such projects, her own priorities are to disseminate information locally. Thus she is not particularly disappointed at the project's outcomes:

What I am much more interested in is publishing about it in our home journals because [network members] abroad, they may be interested about doing these other things internationally or cross-linguistically or cross-culturally but what I would like to do is to publish the result and everything about it the project and the instrument here just to let teachers know. (Interview, January 10, 2003)

In addition, Olivia appreciates the connection made with the project leader in the United Kingdom, who "offered to help with any English papers" she writes (Interview, May 12, 2003).

Olivia's network histories underscore the importance of her strong local network for enabling participation in a formal transnational network. In this instance, her participation in the SOCRATES project required a considerable commitment of time and labor by each country partner. Olivia mobilized the necessary resources by calling on her local network; the project grant enabled her to hire some schoolteachers and graduate students. She also involved her longstanding scholarly colleagues in the research and resulting publications (in process). Her ties to the formally constituted transnational project were weak, having been invited to participate through a connection brokered by someone she could not even identify. Fig. 3 depicts Olivia's networks: her strong, local, durable network as well as ties to the more temporary transnational network. On the left are members of her local network, the two colleagues and students; on the right are the SOCRATES project partners. Here Olivia acts as a network broker for, in particular, one colleague and a student whom she hired for the project.

\subsection{Network history 4: Ernesto, Spain}

Ernesto, 58, is a full professor of psychology and has worked in academia for 23 years. In Spanish his publications include three books, five book chapters, and 17 articles; in English he has published three book chapters and 13 articles, mainly in high-status journals. Ernesto's English proficiency is high and his main objective is publishing in high-ranking English-medium research journals. Nonetheless, he is committed to improving educational practice, thus also publishes in Spanish which allows him to support students who are less proficient in English.

\subsubsection{Network 4.1}

Ernesto has been working over some time to develop a research group that now comprises eight colleagues (from five in 2002) and four post-graduate students. Three subgroups work under his direction on research 
that has been consistently funded by Spanish government grants. Further, he has created a strong, wide-ranging informal, transnational network of connections in Spain and other European countries as well as in the United States; these ties have usually been forged at SIG meetings of academic associations.

\subsubsection{Network 4.2}

At one SIG meeting in 1995, Ernesto made a connection with a French scholar with whom he has maintained ongoing contact, including visits to each other's universities and linking their students to each other's networks. For example, recently a former student and now colleague of Ernesto's spent four months at the French scholar's institution. Ernesto and the French scholar have co-authored (in English) one article and two book chapters; moreover, they have often shared feedback on manuscripts, even when not co-authoring. Ernesto discusses the durability of this tie:

We have this, I would say, not actually permanent but a very fluent communication with my colleague in France. In fact in ... a student of his will come here to work with us, maybe in the future another student of ours will go there. (Interview, February 3, 2003)

Ernesto and the French colleague have also applied twice, unsuccessfully, for a Picasso Action ${ }^{10}$ grant from the French government for a formal two-year bilateral research programme. Nonetheless, even without external funding their collaboration endures.

\subsubsection{Network 4.3}

In 2006, a northern European scholar invited Ernesto to participate in a four-year project funded by the principal investigator's (PI) government. Ernesto's French colleague was also invited, separately, to participate "because [he] did very good research in the issue of $[\mathrm{X}]$... He and an American professor from Pittsburgh, he was there for two years, and they published probably the first papers about [X] in 1994" (Interview, April 25, 2006). The PI had attended a SIG meeting that Ernesto had organized at his university two years earlier; in the meantime they had met at another conference. Ernesto's team made contributions needed by the PI's team, as Ernesto identifies:

They are interested in our collaboration because we have experience in developing [X]. And second, because they do correlational research but not experimental research, we do exactly the opposite. We have no experience in correlational research with a great number of people, very big samples, but we have experience with experiments so we complement each other quite perfectly well. (Interview, April $25,2006)$

The project's common language is English. The grant paid for project members to travel to each other's sites and for Ernesto to attend conferences with local colleagues and post-graduates. Further, three of Ernesto's post-graduate students stayed at the PI's university for up to three months. So far, this collaboration has resulted in five English-medium texts, three of which have been published, as well as one Spanish-medium article under review. The PI has also served on the PhD committee of one of Ernesto's students. The involvement of Ernesto's post-graduate students in these collaborations is not accidental; Ernesto, like Ornella's PhD supervisor, works assiduously to provide students with opportunities to collaborate and co-author. He finds the outcomes highly rewarding: "this is probably one of the things that makes me feel most proud of my job" (Interview, December 19, 2008).

In Ernesto's network histories, therefore, his strong, local, informal network directly supports not only his own participation in strong, transnational networks, but also that of his colleagues and post-graduate students. The invitation from the northern European colleagues came not from a formal initiative but rather as a result of Ernesto's informal network, developed over time and particularly fostered by attending SIG meetings. Fig. 4 maps out Ernesto's local and transnational networks. On the left is the strong, durable, local network comprising eight colleagues and four students. On the right, solid lines show Ernesto's ties to the

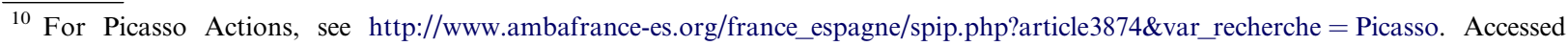
June 3, 2010.
} 
French colleague and the northern European project. Also shown are the ties Ernesto has brokered for his students to the northern European network.

\section{Discussion}

The multilingual scholars discussed here - as well as many in our larger study — entered or created a variety of academic research networks, as summarized in Table 1. Here we analyse their network participation along these dimensions: strong/weak, local/transnational, formal/informal, and durable/temporary. These networks range from those comprising local colleagues and post-graduates to networks created at academic conferences, initiated by electronic mail, brokered by figures such as $\mathrm{PhD}$ supervisors or local colleagues/friends, or sponsored by formal programmes.

The four network histories illustrate how various combinations of network dimensions are significant in terms of supporting scholars' ability to secure English-medium publication. All four scholars have published in English - although not all have achieved publication in high-status journals - as well as published in their local languages. Informal networks have supported all scholars in their publishing efforts; however, some informal networks have been weak, as with Diana, compared with, for example, Ernesto's strong networks. Three of the four scholars are embedded in strong, local, durable networks (Ornella, Olivia, Ernesto) that involve both informal and formal networks. Two scholars have participated in transnational, formal initiatives designed to increase cross-European mobility, connections, and/or collaboration (Ornella, Olivia). However, Olivia's collaboration in the SOCRATES programme, specifically designed to foster collaboration, has not resulted in English-medium publications. In addition, the transnational network Olivia participated in appears temporary, aligned with the life of the grant, although she may be able to activate these latent ties in the future.

A key finding emerging from these analyses, therefore, is the importance of scholars' participation in local networks. In particular, strong, durable local networks appear to provide a base from which scholars can more

Table 1

Scholars' network participation.

\begin{tabular}{|c|c|c|c|c|}
\hline Scholar & Network number/type & How entered & How sustained & Resulting products/activities \\
\hline \multirow[t]{2}{*}{ Ornella } & $\begin{array}{l}\text { 1. Local, informal, } \\
\text { strong, durable }\end{array}$ & Through PhD supervisor & $\begin{array}{l}\text { Became colleague, continued to } \\
\text { collaborate }\end{array}$ & $\begin{array}{l}\text { Seven articles and chapters in } \\
\text { L1 and English }\end{array}$ \\
\hline & $\begin{array}{l}\text { 2. Transnational, } \\
\text { formal, strong, } \\
\text { temporary }\end{array}$ & $\begin{array}{l}\text { Met at conference; } \\
\text { ERASMUS programme }\end{array}$ & Email, visits & Three English-medium articles \\
\hline \multirow[t]{3}{*}{ Diana } & $\begin{array}{l}\text { 1. Local, informal, } \\
\text { durable, weak }\end{array}$ & Shared $\mathrm{PhD}$ supervisor & Face-to-face meetings, email & Conference presentation \\
\hline & $\begin{array}{l}\text { 2. Informal, } \\
\text { transnational, } \\
\text { temporary, weak }\end{array}$ & Invited by colleague & $\begin{array}{l}\text { Isolated experience with } \\
\text { particular set of colleagues }\end{array}$ & $\begin{array}{l}\text { One English-medium book } \\
\text { chapter published }\end{array}$ \\
\hline & $\begin{array}{l}\text { 3. Informal, } \\
\text { transnational, weak, } \\
\text { durable }\end{array}$ & Met at conferences & Meeting at conferences, email & $\begin{array}{l}\text { Conference proceedings in } \\
\text { English; invited talks at } \\
\text { conferences }\end{array}$ \\
\hline \multirow[t]{2}{*}{ Olivia } & $\begin{array}{l}\text { 1. Informal, local, } \\
\text { durable, strong }\end{array}$ & $\begin{array}{l}\text { Developed over time in } \\
\text { local settings }\end{array}$ & $\begin{array}{l}\text { Collaboration on multiple } \\
\text { projects, some grant funded }\end{array}$ & $\begin{array}{l}\text { Five publications in Slovak; } \\
\text { one in English }\end{array}$ \\
\hline & $\begin{array}{l}\text { 2. Formal, } \\
\text { transnational, } \\
\text { temporary, weak }\end{array}$ & $\begin{array}{l}\text { Invited by unknown UK } \\
\text { scholar to participate }\end{array}$ & $\begin{array}{l}\text { Face-to-face meetings, email } \\
\text { during life of grant }\end{array}$ & $\begin{array}{l}\text { Report to EU; manual in } \\
\text { Slovak; one Slovak article in } \\
\text { process }\end{array}$ \\
\hline \multirow[t]{3}{*}{ Ernesto } & $\begin{array}{l}\text { 1. Informal, local, } \\
\text { durable, strong }\end{array}$ & $\begin{array}{l}\text { Created network over } \\
\text { many years }\end{array}$ & $\begin{array}{l}\text { Funded research, face-to-face } \\
\text { collaboration }\end{array}$ & $\begin{array}{l}\text { Six articles and book chapters } \\
\text { in English; five in Spanish }\end{array}$ \\
\hline & $\begin{array}{l}\text { 2. Informal, } \\
\text { transnational, } \\
\text { durable, strong }\end{array}$ & Met at conference & $\begin{array}{l}\text { Meeting at conferences, email, } \\
\text { intermittent collaborations, }\end{array}$ & $\begin{array}{l}\text { Three articles and book } \\
\text { chapters in English }\end{array}$ \\
\hline & $\begin{array}{l}\text { 3. Informal, } \\
\text { transnational, 3-year, } \\
\text { strong }\end{array}$ & $\begin{array}{l}\text { Invited by colleagues to } \\
\text { participate in research } \\
\text { project }\end{array}$ & $\begin{array}{l}\text { Ongoing email, visits funded by } \\
\text { grant, meeting at SIGs, } \\
\text { conferences }\end{array}$ & $\begin{array}{l}\text { Five English publications; one } \\
\text { Spanish article; one } \mathrm{PhD} \text { thesis }\end{array}$ \\
\hline
\end{tabular}


fully participate in transnational networks, both formal and informal. While success at English-medium publishing does not always require participation in transnational networks, overall, scholars who are actively participating beyond their local networks appear to be more likely to secure English-medium publications than those who are not (see also Lillis \& Curry, 2010). Network brokers play a pivotal role in helping scholars to bridge from local to transnational networks; often these brokers are central nodes in local networks, such as Olivia and Ernesto, who forge ties for local network members to bridge to transnational networks. Brokers may also be nodes in other networks and scholars may have weak ties to them, such as Diana's Portuguese colleague, or the UK scholar who invited Olivia to join the SOCRATES project.

Although we are focusing here primarily on scholars' English-medium publishing, various combinations of network dimensions clearly support multilingual scholars' work in other ways, such as sustaining local research projects/networks and publishing in local languages. And although, to varying extents, all scholars share the goal of publishing in English, this is not always their top priority, as in Olivia's case; indeed, commitments to local contexts or local networks may be equally pressing (Curry \& Lillis, 2004; Lillis \& Curry, 2010). In addition, the network histories discussed here reflect a wider pattern evident in our larger study data of disciplinary differences between psychology and education, with psychology scholars generally participating more in stronger networks and education scholars in weaker networks, although there is some evidence that growing pressure on educationalists to publish is resulting in these scholars increasing their network activity.

\section{Conclusions and Implications}

Findings from these network analyses support our previous findings (Lillis \& Curry, 2006a, 2010) that regardless of scholars' proficiency in English or experience with English-medium academic writing, participation in research networks provides an important means of access to English-medium publishing. However, in our data, formal top-down initiatives to create networks seem to be less powerful than informally generated local networks. Other researchers have also studied formally constituted networks, in which "specific incentives exist to encourage formal international linkages among member countries" (Leydesdorff \& Wagner, 2008, p. 317). Examining chemistry networks fostered by EU Framework Programmes, Defazio et al. (2009) found that "the overall impact of collaboration within funded networks is weak" (p. 293). Likewise, Melin (2000) asserts that personally created (informal, in our terms) networks are more likely to be productive than formally constituted networks. Defazio et al. (2009) point out that networks sponsored by formal initiatives may take longer to "achieve effective collaborations when compared to networks with pre-funding collaborative relationships" (p. 296). Indeed, the findings we present here throw into relief the important role played by local networks, which are often stronger and more durable than transnational networks, in supporting access to transnational networks that can offer the resources needed for English-medium publishing. As well, local network participation appears to provide additional benefits in terms of conducting and disseminating research and building local research structures.

These findings have implications for both individual scholars and institutions and for larger policy bodies. Individual scholars might consider how to participate in local and transnational networks and to find the resources needed to do so. Our own and others' research (e.g., Canagarajah, 1996; Melin, 2000) has highlighted the material resources implicated in achieving this goal: funds for conference and research travel rank among the key resources involved in research and publishing activities. At the same time, our analyses illustrate the challenges and complexities of participating in and sustaining networks, which depend on but go beyond material resources. For example, scholars who attend conferences or SIG meetings may still have uneven access to making personal connections such as those underpinning Ernesto's durable transnational networks. In addition, scholars' comfort levels with making these personal connections may vary. Ideally, those who are already established within networked activity such as Ornella's $\mathrm{PhD}$ supervisor will act as brokers facilitating such connections, but not everyone has access to such brokers. Quite likely, some of the burden of making network ties falls on scholars' own shoulders. Ornella exemplifies a scholar building on her brokered network ties by expanding her contributions to networks, for instance, by helping to organize conferences - to date, some seven conferences in various European locations.

Our findings also have implications for institutions and larger policy bodies aiming to support scholars' research collaboration and productivity more broadly. The rise of formal programmes to foster collaboration 
attests to the belief that such programmes will achieve the desired results. However, a longitudinal view is important: Defazio et al. (2009) offer a caveat on prematurely evaluating formal initiatives, asserting that while immediate increases in productivity may not be visible, such initiatives "may be an important promoter of effective collaborations in the longer run" (p. 293). Over the longer term, therefore, it is possible that formally constituted academic research networks will be effective. However, the participants in Melin's (2000) study questioned the usefulness of programmes that encourage collaborations with specific partners (i.e., partners from a range of nations), arguing instead for networks to be generated by individual scholars. If, as Katz and Martin claim, and our study supports, "most collaborations begin informally and are often the result of informal conversation" (1997, p. 4), this notion supports Melin's proposal that:

providing travel money to the researchers might sound luxurious but is in most cases beneficial; e-mail and phones are not enough even when two people already know each other, they have to meet personally now and then, and it is naturally even harder to make a new contact without meeting face to face. (p. 39)

Thus gaining access to and participating in academic research networks - both local and transnationalappears to be crucial to multilingual scholars' success at English-medium publication. Local, durable networks support scholars' transnational collaborations - and, ultimately, English-medium journal publications. Investment in academic research networks may be best directed at informal network building rather than supporting formal network programmes.

\section{Acknowledgements}

We wish to thank the scholars who have participated in our study since 2001; our universities, the Open University, UK, and the University of Rochester, US; the UK's Economic and Social Research Council (RES-000-22-0098); and the British Academy for support of this research. Thanks also to Christopher Penders at the University of Rochester for help with diagrams.

\section{References}

Barton, D., \& Hamilton, M. (1998). Local literacies: Reading and writing in one community. London: Routledge.

Barton, D., \& Padmore, S. (1994). Roles, networks, and values in everyday writing. In D. Graddol, J. Maybin, \& B. Stierer (Eds.), Researching language and literacy in social context (pp. 205-223). Clevedon, UK: Multilingual Matters.

Bazerman, C. (1988). Shaping written knowledge: The genre and activity of the experimental article in science. Madison: University of Wisconsin Press.

Belcher, D. (2007). Seeking acceptance in an English-only research world. Journal of Second Language Writing, 16(1), 1-22.

Boissevain, J. (1987). Social network. In Sociolinguistics: An international handbook of the science of language and society (Vol. 1, pp. 64 69).

Bourdieu, P. (1985). The forms of capital. In J. G. Richardson (Ed.), Handbook of theory and research for the sociology of education (pp. 241-258). New York: Greenwood Press.

Bourdieu, P. (1990). The logic of practice (R. Nice, Trans.). Stanford, CA: Stanford University Press.

Burt, R. S. (2000). Decay functions. Social Networks, 22, 1-28.

Burt, R. S. (2002). Bridge decay. Social Networks, 24, 333-363.

Canagarajah, A. S. (1996). "Non-discursive" requirements in academic publishing, material resources of periphery scholars, and the politics of knowledge production. Written Communication, 13(4), 435-472.

Canagarajah, A. S. (2002). A geopolitics of academic writing. Pittsburgh: University of Pittsburgh Press.

Casanave, C. (1998). Transitions: The balancing act of bilingual academics. Journal of Second Language Writing, 7(2), 175-203.

Carolan, B. V., \& Natriello, G. (2005). Data-mining journals and books: Using the science of networks to uncover the structure of the educational research community. Educational Researcher (April), 25-33.

Curry, M. J., \& Lillis, T. M. (2004). Multilingual scholars and the imperative to publish in English: Negotiating interests, demands, and rewards. TESOL Quarterly, 38(4), 663-688.

Defazio, D., Lockett, A., \& Wright, M. (2009). Funding incentives, collaborative dynamics and scientific productivity: Evidence from the EU framework program. Research Policy, 38, 293-305.

Ferenz, O. (2005). EFL writers' social networks: Impact on advanced academic literacy development. Journal of English for Academic Purposes, 4, 339-351.

Fingeret, S. (1983). Social networks: A new perspective on independence and illiterate adults. Adult Education Quarterly, 33(3), $133-146$.

Flowerdew, J. (2000). Discourse community, legitimate peripheral participation, and the nonnative-English-speaking scholar. TESOL Quarterly, 34(1), 127-150. 
Flowerdew, J. (2001). Attitudes of journal editors to nonnative speaker contributions. TESOL Quarterly, 35(1), 121-150.

Gee, J. P. (1998). What is literacy? In V. Zamel \& R. Spack (Eds.), Negotiating academic literacies: Teaching and learning across languages and cultures (pp. 51-60). Mahwah, NJ: Lawrence Erlbaum.

Gunnarson, B.-L. (1997). The writing process from a sociolinguistic viewpoint. Written Communication, 14(2), $139-188$.

Granovetter, M. (1972). The strength of weak ties. American Journal of Sociology, 78(6), 1360-1380.

Granovetter, M. (1983). The strength of weak ties: A network theory revisited. Sociological Theory, 1, $201-233$.

Ivanič, R., \& Satchwell, C. (2007). Networking across boundaries: Connecting and transforming the literacies of research, practice and theory. Journal of Applied Linguistics, 4(1), 101-124.

Jones, C., Turner, J., \& Street, B. (Eds.). (1999). Students writing in the university: Cultural and epistemological issues. Amsterdam: John Benjamins.

Kachru, B. (2001). World Englishes. In R. Mesthrie (Ed.), Concise encyclopedia of sociolinguistics (pp. 519-524). New York: Elsevier.

Katz, J. S., \& Martin, B. (1997). What is research collaboration? Research Policy, 26, 1-18.

Lea, M. R., \& Street, B. V. (1998). Student writing in higher education: An academic literacies approach. Studies in Higher Education, 23(2), 157-172.

Leander, K., \& Lovvorn, J. (2006). Literacy networks: Following the circulation of texts, bodies, and objects in the schooling and online gaming of one youth. Cognition \& Instruction, 24(3), 291-340.

Leydesdorff, L., \& Wagner, C. (2008). International collaboration in science and the formation of a core group. Journal of Informetrics, 2 , $317-325$.

Lillis, T. (2001). Student writing: Access, regulation and desire. London: Routledge.

Lillis, T. (2008). Ethnography as method, methodology, and "deep theorizing": Closing the gap between text and context in academic writing research. Written Communication, 25(3), 353-388.

Lillis, T. M., \& Curry, M. J. (2006a). Professional academic writing by multilingual scholars: Interactions with literacy brokers in the production of English-medium texts. Written Communication, 23(1), 3-35.

Lillis, T. M., \& Curry, M. J. (2006b). Reframing notions of competence in scholarly writing: From individual to networked activity. Revista Canaria de Estudios Ingleses, 53, 63-78.

Lillis, T., \& Curry, M. J. (2010). Academic writing in a global context: The politics and practices of publishing in English. London: Routledge.

Lin, N. (2001). Building a network theory of social capital. In N. Lin, K. Cook, \& R. Burt (Eds.), Social capital: Theory and research. New York: Aldine de Gruyter.

Melin, G. (2000). Pragmatism and self-organization: Research collaboration at the individual level. Research Policy, $29,31-40$.

Mitchell, J. (1984). Typicality and the case study. In R. F. Ellen (Ed.), Ethnographic research: A guide to conduct (pp. 238-241). New York: Academic Press.

Moody, J. (2004). The structure of a social science collaboration network: Disciplinary cohesion from 1963 to 1999 . American Sociological Review, 69, 213-238.

Morgan, D., Neal, M., \& Carder, P. (1997). The stability of core and peripheral networks over time. Social Networks, 19(1), 9-25.

Newman, M. (2001). The structure of scientific collaboration networks. PNAS, 98(2), 404-409.

Plickert, G., Coté, R., \& Wellman, B. (2007). It's not who you know, it's how you know them: Who exchanges what with whom? Social Networks, 29, 405-429.

Polo, F. J., \& Varela, M. C. (2009). English for research purposes at the University of Santiago de Compostela: A survey. Journal of English for Academic Purposes, 8, 152-164.

Polodny, J., \& Page, K. (1998). Network forms of organization. Annual Review of Sociology, 24, 57-76.

Portes, A. (2000). The two meanings of social capital. Sociological Forum, 15(1), 1-12.

Prior, P. (1998). Writing/disciplinarity: A sociohistoric account of literate activity in the academy. Mahwah, NJ: Lawrence Erlbaum.

Scott, J. (1991). Social network analysis: A handbook. London: SAGE.

Stake, R. (2000). Case studies. In N. Denzin \& Y. S. Lincoln (Eds.), Handbook of qualitative research (2nd ed., pp. 435-454). Thousand Oaks, CA: SAGE.

Street, B. V. (2003). What's new in new literacy studies? Current Issues in Comparative Education, 5(2), 1-14.

Suitor, J., Wellman, B., \& Morgan, D. (1997). It's about time: how, why, and when networks change. Social Networks, $19,1-7$.

Swales, J. (2004). Research genres. Oxford: Oxford University Press.

Uzuner, S. (2008). Multilingual scholars' participation in core/global academic communities: A literature review. Journal of English for Academic Purposes, 7, 250-263.

Wagner, C., \& Leydesdorff, L. (2005). Network structure, self-organization, and the growth of international collaboration in science. Research Policy, 34, 1608-1618.

Wallerstein, I. (1991). Geopolitics and geoculture. Cambridge: Cambridge University Press.

Wellman, B. (1999). Networks in the global village: Life in contemporary communities. Boulder, CO: Westview Press.

Wellman, B., \& Berkowitz, S. D. (1988). Introduction. In B. Wellman \& S. D. Berkowitz (Eds.), Social structures: A network approach (pp. 1-13). Cambridge: Cambridge University Press. 